\title{
100 years after his birth Guttmann's message lives on
}

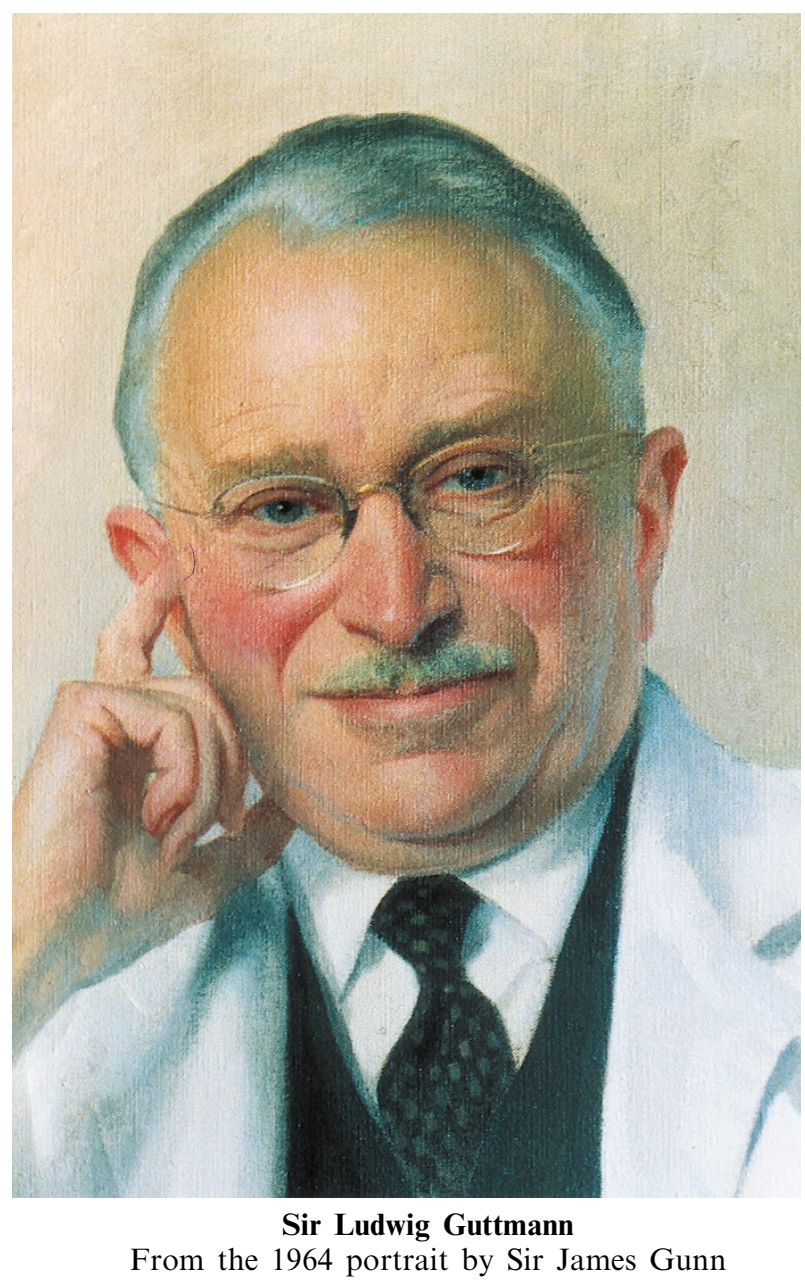

Most of the present members of the International Medical Society of Paraplegia have never met Ludwig Guttmann, the Society's First President. He was born on 3rd July 1899 in Upper Silesia. He studied medicine in Breslau and Freiburg. He studied neurosurgery under Foerster in Breslau (Foerster was a 'first generation Neurosurgeon') and Guttmann adopted Foerster's meticulous attention to accuracy and detail, both in neurological examination and in surgical technique.

He came to England as a refugee in 1939 and was given a research post in Oxford. Much of his research at that time involved the use of Quinizarin Powder to study disorders of sweating associated with neurological lesions. The powder was applied to the patient's whole body and where they sweated they turned purple! He was not happy at Oxford as he had no clinical responsibility.

In 1944 he was asked to lead a spinal unit for injured servicemen at Stoke Mandeville Hospital. In those days few tetraplegics lived to reach a spinal unit and the paraplegics had already developed severe complications, in particular pressure sores and urinary tract infections. Most of the patients died within a year of injury. In Guttmann's words paraplegics were suffering from 'a delayed fatal injury'. The purpose of the spinal units was to remove these doomed patients from the military hospitals.

Guttmann saw the setting up of the Spinal Unit as an opportunity to prove that complications could be overcome. He developed a team approach (strongly led from the top) with meticulous and detailed attention to the repetitive tasks needed to prevent complications. Having proved that it was possible to treat complications, he then demonstrated that it was much easier to prevent complications than to treat them and from this grew the concept of early admission to specialized spinal injury units. Having produced a cohort of paralysed but otherwise healthy young men, he pursued the physical, psychological and social rehabilitation of his patients with equal vigour. At that time there was no speciality of medical rehabilitation and close teamwork between doctors, nurses and therapists was unknown.

During the 1950's the fame of Stoke Mandeville and its patients spread throughout the world and although there was some published physiological research, in order to learn Guttmann's methods it was necessary to visit Stoke Mandeville Hospital. This changed with the founding of the International Medical Society of Paraplegia of which Guttmann was the First President. As he was also the Editor of its journal, then known as 'Paraplegia' a stream of publications from Stoke Mandeville emerged and was eventually consolidated into his book 'Spinal Cord InjuriesComprehensive Management \& Research'. Following his retirement from clinical work in 1966 he concentrated on the development of sport for the paralysed. He was instrumental in setting up the early Paralympics and was still active in this field at the time of his death on 18 March 1980.

Those who never met Guttmann wonder how he achieved so much. He was a small man of immense energy and when he became animated he seemed to grow in size and almost filled the room. He was both loved and feared and inspired great loyalty in his followers. Once you had fallen under his spell there was little chance of escape! He personally Chaired the Scientific Sessions of the early Meetings of the International Medical Society of Paraplegia and there are still a few Senior Members of our profession alive who were 'mauled' by him in debate! He constantly tried to raise the scientific level of the Society's Meetings and Journal. His Obituary by $\mathbf{J}$ Cosbie 
Ross and Phillip Harris was published in Paraplegia 1980; 18: $153-156$.

I personally owe my training and career to Ludwig. The accompanying portrait, painted in 1964, shows him at the height of his powers in a genial mood. His main message, that 'spinal cord injured patients should be transferred as soon as possible to a specialized spinal injuries unit' remains valid today.

Hans Frankel 